\title{
Induction of thermogenic adipocytes: molecular targets and thermogenic small molecules
}

\author{
No-Joon Song ${ }^{1}$, Seo-Hyuk Chang ${ }^{1}$, Dean Y Li ${ }^{2}$, Claudio J Villanueva ${ }^{3}$ and Kye Won Park ${ }^{1}$ \\ Adipose tissue is a central metabolic organ that controls energy homeostasis of the whole body. White adipose tissue (WAT) \\ stores excess energy in the form of triglycerides, whereas brown adipose tissue (BAT) dissipates energy in the form of heat \\ through mitochondrial uncoupling protein 1 (Ucp1). A newly identified adipose tissue called 'beige fat' (BAT-like) is produced \\ through a process called WAT browning. This tissue mainly resides in WAT depots and displays intermediate characteristics of \\ both WAT and BAT. Since the recent discovery of BAT in the human body, along with the identification of molecular targets for \\ BAT activation, stimulating energy expenditure has been considered as a great strategy to treat human obesity and metabolic \\ diseases. Here we summarize recent findings regarding molecular targets and thermogenic small molecules that can stimulate \\ BAT and increase energy expenditure, with an emphasis on possible therapeutic applications in humans.
}

Experimental \& Molecular Medicine (2017) 49, e353; doi:10.1038/emm.2017.70; published online 7 July 2017

\section{INTRODUCTION}

Obesity is caused by an imbalance between energy intake and energy expenditure. ${ }^{1}$ The excess energy is stored as triglycerides in adipocytes. The prevalence of obesity and its related metabolic diseases is increasing worldwide. However, current approaches to combat obesity are limited due to their adverse side effects. For example, Orlistat, a well-known medication that blocks fat digestion, causes multiple side effects, including diarrhea, body aches, headache and nausea. ${ }^{2-4}$ Phentermine is another widely used drug that suppresses appetite. However, phentermine targets the central nervous system and can cause severe mental changes and sensory deficits. ${ }^{5}$ The recent discovery of brown adipose tissue (BAT) in adults has brought about a new interest in alternative therapies that activate BAT to treat obesity and associated metabolic diseases. ${ }^{6-8}$ These studies have thus fueled the development of therapeutic strategies that increase energy expenditure.

The major site of energy storage is the white adipose tissue (WAT). BAT generates heat by oxidation of stored energy with the help of uncoupling protein 1 (Ucp1). Cold exposure and adrenergic activation can simulate Ucp1 expression and activity. $^{8-10}$ Beige adipocyte (BAT-like) is another subtype within white adipose tissue. The cells that make up this tissue are called brite (brown in white) or brown-like adipocytes. Similar to brown adipocytes, beige adipocytes also express
Ucp1, which allows protons to cross the inner mitochondrial membrane, resulting in increased oxygen consumption and heat generation. ${ }^{8,11}$ Heat generated through the activation of brown and beige adipocytes can protect mammals against cold exposure. This process greatly affects energy homeostasis and whole body metabolism.

The activation and/or induction of thermogenic adipocytes can lead to significant body weight reduction and improved metabolic parameters in animal studies. Thus, a promising therapeutic strategy to increase the energy expenditure is to use chemical agents to stimulate the induction of beige adipocytes or the activation of brown adipocytes (Figure 1 and Table 1). Several compounds, including berberine, butein, salsalates, fucoxanthin and peroxisome proliferator-activated receptor $\gamma$ (Ppary) agonists, have been identified as they exhibit great potential to activate/induce BAT or beige fat. ${ }^{12-16}$ This review summarizes findings regarding the molecular mechanisms responsible for the induction of thermogenic adipocytes (Figure 1). This review also summarizes thermogenic small molecules (Table 1) that are derived from plants (natural thermogenic compounds), artificially synthesized small molecules (synthetic thermogenic compounds) or endogenous small molecules (endogenous thermogenic compounds). Finally, the possible therapeutic applications of these thermogenic compounds in human diseases are discussed.

\footnotetext{
${ }^{1}$ Department of Food Science and Biotechnology, Sungkyunkwan University, Suwon, Korea; ${ }^{2}$ Department of Medicine, Program in Molecular Medicine, University of Utah, Salt Lake City, UT, USA and ${ }^{3}$ Department of Biochemistry, University of Utah School of Medicine, Salt Lake City, UT, USA Correspondence: Dr KW Park, Department of Food Science and Biotechnology, Sungkyunkwan University, 2066 Seobu-ro, Jangan-gu, Suwon 16419, Korea.

E-mail: kwpark@skku.edu

Received 26 November 2016; revised 25 December 2016; accepted 30 December 2016
} 


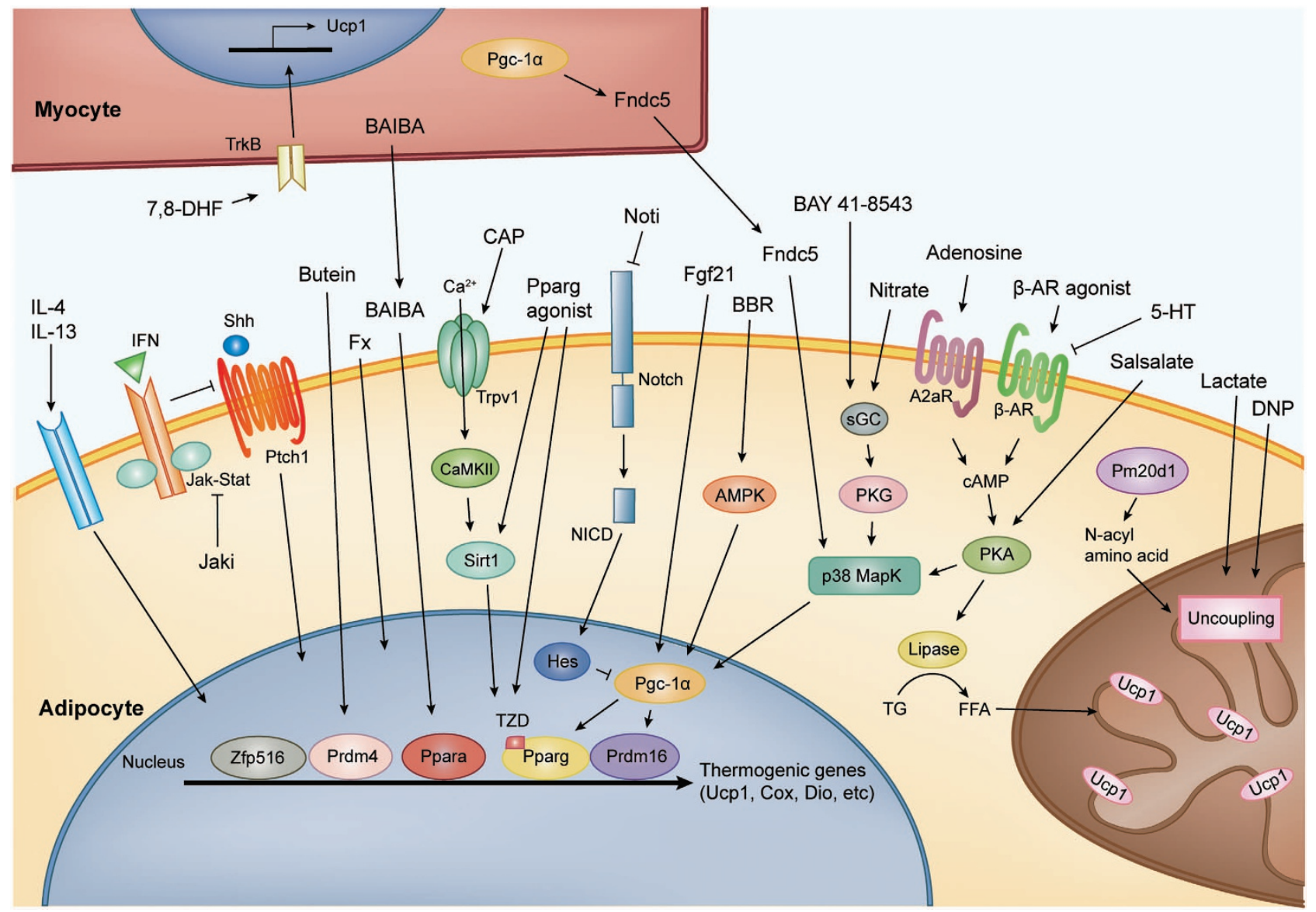

Figure 1 Molecular mechanism of thermogenic induction by small molecules. Activation of cell surface receptors, such as Trpv1, $\beta 3-A R$, Ptch1 and A2aR, in adipocytes and TrkB in muscles involves cellular signaling cascades (PKA, PKG, Sirt1, AMPK and p38 MAPK), transcriptional regulators (Prdm family, Pgc-1 $\alpha$, Ppar family and Zfp516) and cytokines (IL-4 and IL-13) to induce Ucp1 expression. This process also stimulates brown adipocytes followed by Ucp1-mediated heat production. Natural thermogenic small molecules, such as berberine, butein, capsaicin and fucoxanthin, activate thermogenic transcriptional factors through their cell surface receptors or by modulating cellular signaling cascades in adipocytes. 7,8,DHF stimulates TrkB and induces sustained AMPK activity in muscles. Synthetic thermogenic compounds Ppar agonists, Jak inhibitors, Notch inhibitors, salsalate, $\beta$-AR agonists, BAY $41-8543$ and DNP can also increase thermogenesis. Thermogenic small molecules, including serotonin, lactate, BAIBA, nitrate, and adenosine, are endogenously produced upon certain stimuli to increase thermogenic responses. BAIBA and lactate secreted from myocytes upon exercise can act upon white adipocytes and stimulate thermogenic conversion. A2aR, adenosine A2a receptor; AMPK, AMP-activated protein kinase; $\beta$-AR, $\beta$-adrenergic receptor; BAIBA, $\beta$-aminoisobutyric acid.; BBR, berberine; CaMKII, Ca2/calmodulin-dependent protein kinase II; CAP, capsaicin; 7,8 DHF, 7,8 dihydroxyflavone; DNP, dinitrophenol; Fx, fucoxanthin; Hes, hairy and enhancer of split; IFN, interferon; Jaki, Jak inhibitor; p38 MAPK, p38 mitogen-activated protein kinase; Pgc-1 $\alpha$, peroxisome proliferator-activated receptor gamma coactivator-1 $\alpha$; PKA, protein kinase A; PKG, protein kinase G; Pm20d1, peptidase M20 domain-containing 1; Ppar, peroxisome proliferator-activated receptor; Prdm, PR domain-containing proteins; Ptch1, Patched-1; SGC, soluble guanylate cyclase; Shh, Sonic hedgehog; Sirt1, Sirtuin 1; TrkB, tropomyosin-related kinase receptor B; Trpv1, transient receptor potential cation channel subfamily $\mathrm{V}$ member 1 ; TZD, thiazolidinedione; Ucp1, uncoupling protein 1; Zfp516, zinc finger protein 516; Noti, Notch inhibitor.

\section{MOLECULAR TARGETS FOR INDUCING THERMOGENIC ADIPOCYTES}

\section{Uncouplers}

Uncoupling protein 1. Ucp1 is a multipass transmembrane protein that is highly expressed in the mitochondria of thermogenic adipocytes, brown adipocytes and beige adipocytes. Ucp1 modulates the proton gradient between the mitochondrial matrix and the intermembrane space and generates heat by uncoupling the respiratory chain with a low rate of ATP production. ${ }^{17,18}$ Because the proton gradient is essential for ATP synthesis, the activity of Ucp1 is tightly regulated. Normally, Ucp1 is activated in response to cold exposure. Cold exposure stimulates the secretion of noradrenaline from the sympathetic nervous system, leading to the activation of adrenergic receptors and the stimulation of the thermogenic response in adipocytes. ${ }^{9,19}$ Leptin and other factors that stimulate free fatty acid release can activate BAT or beige fat through direct binding to fatty acids with Ucp1. ${ }^{20-22}$ Cold exposure also increases Ucp1-dependent thermogenesis by increasing the levels of reactive oxygen species in the mitochondria and sulfenylation of Ucp $1 .{ }^{23} \mathrm{Ucp} 1$ transcription is also regulated 
Table 1 Thermogenic small molecules and their biological actions

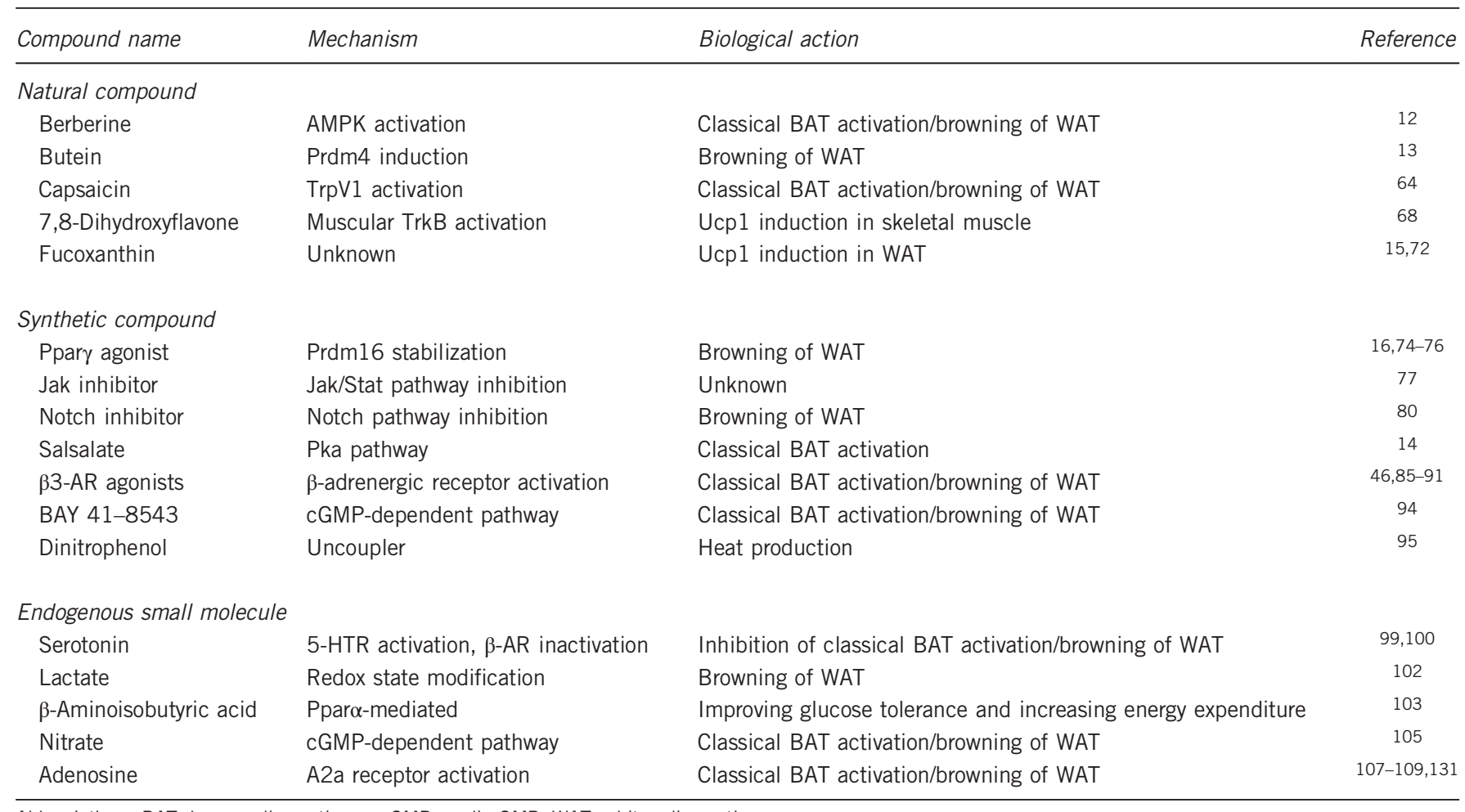

Abbreviations: BAT, brown adipose tissue; cGMP, cyclic GMP; WAT, white adipose tissue.

by multiple transcription factors, including Ppary, PR domaincontaining 16 (Prdm16) and peroxisome proliferator-activated receptor gamma coactivator-1 alpha $(\operatorname{Pgc}-1 \alpha){ }^{24-29}$ Thus, to generate functionally active thermogenic adipocytes, regulation of Ucp1 transcription and activity should be carefully considered.

Peptidase M20 domain-containing 1. Most studies related to the thermogenic action of adipocytes have focused on the expression and activity of Ucpl due to limited knowledge regarding thermogenic enzymes. Nonetheless, questions have been steadily raised for the presence of Ucp1-independent thermogenic processes. Until recently, the underlying mechanism of Ucpl-independent thermogenic processes has been unclear. ${ }^{30,31}$ Peptidase M20 domain-containing 1 (Pm20d1) is a bi-directional $N$-acyl amino acid producing enzyme (from fatty acids and amino acids) that has been recently identified as a new thermogenic molecule that functions independent of Ucp1. N-Acyl amino acids processed from Pm20d1 can directly bind to the mitochondria and function as endogenous uncouplers, leading to increased mitochondrial respiration to replenish the ATP pool. Mice injected with Pm20d1-containing adenovirus have been found to be protected from diet-induced obesity via an increase in energy expenditure. ${ }^{32}$ Moreover, injection of $N$-acyl amino acid itself can also improve glucose metabolism and increase energy expenditure. $^{32}$

\section{Transcriptional regulators}

$P R$ domain-containing protein. PR domain-containing protein 16 (Prdm16) was first identified as a powerful transcriptional regulator of brown adipogenesis via modulation of the muscle-to-brown fat switch. ${ }^{26}$ Forced expression of Prdm16 in white adipocyte precursor cells can lead to the induction of brown adipocyte-selective genes, resulting in higher metabolic rates. ${ }^{25,26,33}$ Transgenic mice expressing Prdm16 in WAT depots are protected from obesity due to improved glucose metabolism. ${ }^{34}$ Consistently, adipocyte-specific knockout of Prdm16 exacerbates obesity and glucose homeostasis. ${ }^{35}$ Mechanistic studies have further revealed that Prdm16 interacts with multiple transcriptional regulators, including Ppar $\gamma$, euchromatic histone-lysine $N$-methyltransferase 1 (Ehmt1), CCAAT/enhancer binding protein beta $(\operatorname{Cebp} \beta)$ and transducing-like enhancer of split 3 (Tle3). ${ }^{26,36-38}$ Another transcriptional Ucp1 regulator, Prdm4, has also been recently identified. Loss of $\operatorname{Prdm} 4$ can increase white adipocyte differentiation while suppressing the expression of thermogenic genes in beige and brown adipocytes. Mice lacking Prdm4 have shown increased weight gain and insulin resistance on a high-fat diet. ${ }^{13}$ Therefore, targeting pathways to increase Prdm16/Prdm4 expression may lead to new therapeutic avenues for obesity and diabetes.

Peroxisome proliferator-activated receptor gamma coactivator$1 \alpha$. Peroxisome proliferator-activated receptor gamma coactivator-1 $\alpha$ (Pgc-1 $\alpha)$ was identified as a binding partner of Ppary in brown adipocytes. ${ }^{27}$ Pgc- $1 \alpha$ plays a critical role in 
cold-mediated WAT browning downstream of $\beta 3$-adrenergic receptor signaling pathways. $\beta 3$-Adrenergic receptor agonist or cold exposure can activate MAPK and cAMP signaling to modulate the activity and expression of Pgc-1 $\alpha$. The ectopic expression of Pgc- $1 \alpha$ in white adipocytes induces a brown adipocyte-selective gene program and increases cellular respiration. ${ }^{28,29}$ Mechanistic studies have revealed that Pgc- $1 \alpha$ binds with multiple transcription factors to regulate brown adipocyte-specific gene programs. Interaction of Pgc-1 $\alpha$ with Prdm16 and mediator of RNA polymerase II transcription subunit 1 (Med1) can increase the expression of Ucp1. ${ }^{39,40}$ Pgc- $1 \alpha$ also binds with interferon regulatory factor 4 (Irf4) to control transcription of the Ucp 1 mRNA. ${ }^{41}$

Forkhead box protein c2. Forkhead box protein c2 (Foxc2) is a well-known transcription factor that regulates adipocyte differentiation and metabolism. ${ }^{42-44}$ Foxc2 transgenic mice have increased beige fat formation and BAT activity, subsequently increasing the rates of oxygen consumption and energy expenditure. Foxc2-activated thermogenic adipocytes are mediated by an elevated level of $\beta$-adrenergic receptor-PKA signaling, leading to higher Ucp1 expression. ${ }^{45}$

Zinc finger protein 516. Cold-inducible zinc finger protein 516 (Zfp516) was identified by its interaction with the proximal region of the Ucp1 promoter. ${ }^{46,47} \operatorname{Prdm} 16$ and Zfp516 complexes can also induce the expression of Ucp1 and Pgc-1 $\alpha$. Knockout of Zfp516 has caused embryonic lethality, with a significant reduction in BAT mass. Conversely, adipocyte-specific expression of Zfp516 can activate thermogenic adipocytes in WAT depots and prevent diet-induced obesity by increasing energy expenditure. ${ }^{46}$

\section{Hormones}

Irisin. Although intrinsic transcription factors regulating thermogenic adipocytes have been widely studied, extrinsic factors are relatively less elucidated. One important hormone that induces beige fat from WAT is irisin. ${ }^{48,49}$ Transgenic mice expressing Pgc-1 $\alpha$ in muscles have increased beige fat and are protected from diet-induced obesity. Subsequent studies have shown that induction of thermogenic adipocytes by muscle Pgc-1 $\alpha$ is mediated by muscle-secreted irisin. Injection of irisin (also called fibronectin type III domaincontaining protein 5)-expressing adenovirus can induce beige fat formation with increased thermogenic gene program expression, improve glucose metabolism, and increase energy expenditure. ${ }^{48}$ Circulating levels of irisin appear to be correlated with acute exercise. However, its physiological roles in humans remain to be determined. ${ }^{50}$

Fibroblast growth factor 21. Fibroblast growth factor 21 (Fgf21) has been studied as a critical metabolic regulator in multiple organs, including adipose tissues, the liver and the pancreas. ${ }^{51}$ Fgf21-knockout mice have abnormal gene expression patterns and body temperatures when exposed to low temperatures. Therapeutic doses of Fgf21 can lower glucose levels shortly after being administered in both mice and humans. The impaired expression of a thermogenic gene program is also associated with a reduced level of Pgc- $1 \alpha$ protein in adipocytes. ${ }^{52}$

\section{Cytokines}

Type II cytokines, including IL-4 and IL-13, play beneficial roles in adipose tissue remodeling. Cold exposure activates eosinophils to secrete IL-4 and IL-13, resulting in alternative activation of macrophages in adipose tissues. These activated macrophages in turn produce catecholamines, resulting in the induction of WAT browning and of the thermogenic capacity of BAT. ${ }^{53}$ It has also been demonstrated that IL-4 and IL-13 are critically involved in the commitment of beige adipocytes from the progenitors in WAT depots, thereby revealing dual roles of type II cytokines in the induction of thermogenic adipocytes. ${ }^{54}$

\section{NATURAL THERMOGENIC COMPOUNDS}

\section{Berberine}

Berberine is a natural quaternary ammonium salt found in medicinal herbal plants including barberries (Berberis spp.), Oregon grape holly (Mahonia aquifolium), goldenseal (Hydrastis canadensis) and Chinese goldthread (Coptis chinensis). ${ }^{55-57}$ These medicinal plants are mainly used to treat diarrhea and metabolic diseases. Previous studies have shown that berberine-treated $\mathrm{db} / \mathrm{db}$ mice can be protected from obesity by increasing energy expenditure via the activation of BAT and browning of inguinal but not epididymal WAT. Mechanistic studies have shown that the AMPK/Pgc-1 $\alpha$ pathway is responsible for the induction of Ucp1 expression and brown adipocyte-selective gene program expression. ${ }^{12}$

\section{Butein}

Butein, a naturally occurring chalcone, is isolated from the medicinal Chinese lacquer tree (Toxicodendron vernicifluum). ${ }^{58}$ Toxicodendron vernicifluum has been shown to possess anti-inflammatory, anti-obesity and anti-cancer activities. ${ }^{59-61}$ Butein also has the ability to induce Ucp 1 mRNA expression. Although the in vivo efficacy of butein in obese or diabetic mice has not yet been demonstrated, butein has been utilized to identify Prdm4 as a key driver of the brown and beige fat gene program. Prdm4 knockdown and overexpression studies have further revealed that Prdm4 can stimulate Ucp1 expression and increase energy expenditure. ${ }^{13}$

\section{Capsaicin}

Capsaicin is one of the bio-active compounds found in chili peppers. ${ }^{62}$ This compound produces a burning sensation in humans. Capsaicin has been shown to be able to activate transient receptor potential cation channel subfamily $\mathrm{V}$ member 1 (TrpV1), resulting in anti-obese effects in mice. ${ }^{63,64}$ Capsaicin treatment can increase BAT activity and Ucp1 mRNA expression in inguinal WAT, leading to weight loss. ${ }^{65}$ Similar to the action of capsaicin, the capsinoids capsiate, dihydrocapsiate and nordihydrocapsiate can also activate TrpV1 and subsequently increase energy metabolism; however, they do 
not cause pungency. ${ }^{66}$ Thus, further investigation of capsinoids may also provide alternative treatment for metabolism-related diseases.

\section{7,8-Dihydroxyflavone}

7,8-Dihydroxyflavone (7,8-DHF) is a naturally occurring flavone found in primula tree (Godmania aesculifolia) leaves. ${ }^{67}$ This flavone has been shown to have beneficial effects on central nervous system-related diseases. ${ }^{68,69}$ In metabolic diseases, 7,8-DHF-treated female, but not male, mice have been shown to be resistant to obesity induced by a high-fat diet. This resistance can be explained by increased expression of Ucp1 in muscles accompanied by increased energy expenditure without appetite suppression. ${ }^{70}$ However, the mechanism for its differential effects in the different sexes is currently unclear. Regardless, it is known that 7,8-DHF treatment increases Ucp1 expression and AMPK activity via TrkB (tropomyosin-related kinase receptor B) in skeletal muscles. The anti-obese effect of 7,8-DHF is blunted in TrkB-knockout mice, further indicating that TrkB plays a crucial role in 7,8-DHF-mediated anti-obese effects. $^{70}$

\section{Fucoxanthin}

Fucoxanthin is a highly enriched carotenoid found in edible seaweeds. ${ }^{71}$ Fucoxanthin has been shown to prevent obesity, metabolic disease and cancer. ${ }^{72,73}$ Fucoxanthin treatment in mice can reduce whole body weight and abdominal fat. These improvements in metabolic parameters are also related to the induction of Ucp1 protein levels in white adipose tissue. ${ }^{15,74}$

\section{SYNTHETIC THERMOGENIC COMPOUNDS}

\section{Ppar $\gamma$ agonists}

Ppary, a nuclear receptor, belongs to the class of transcription factors with a characteristic ligand binding domain. Ppary is regarded as the master regulator of adipogenesis. ${ }^{6,75}$ Treatment with Ppary agonists can stimulate the formation of beige adipocytes. However, its underlying mechanism remains unclear. ${ }^{76-78}$ A recent study has indicated that Ppary agonists, particularly rosiglitazone, can induce beige adipocyte formation through stabilizing the Prdm16 protein. The induction of beige adipocyte by rosiglitazone is blunted in Prdm16-knockdown cells, further indicating a role for $\operatorname{Prdm} 16$ in rosiglitazonemediated WAT browning. ${ }^{16}$

\section{JAK inhibitors}

In a recent study, Moisan et al. ${ }^{79}$ screened small-molecule inducers of human beige fat from white adipocytes and identified JAK inhibitors-tofacitinib and R406-as key molecules. JAK inhibitors can reduce lipid-droplet size, increase cellular oxygen consumption and increase Ucp1 expression in human adipocytes. These JAK inhibitor effects could be due to the repression and activation of the interferon and hedgehog signaling pathways, respectively. ${ }^{79}$

\section{Notch inhibitor}

Notch signaling is a critical pathway in the central nervous system. This pathway also plays an important role in metabolic regulation. ${ }^{80,81}$ Adipocyte-specific deletion of notch1 or Rbpj (a downstream activator of notch signaling) in mice can induce beige adipocytes, resulting in an increase in whole body energy expenditure. Treatment with the chemical notch inhibitor DAPT has shown similar upregulation of brown fat-specific genes, including Ucp1, in cultured and primary adipocytes. Injection of another notch inhibitor, DBZ, in leptin-deficient mice resulted in a reduction in body weight gain and improvement in metabolic parameters. ${ }^{82}$

\section{Salsalate}

Salsalate is a powerful anti-inflammatory drug originating from salicylates. This drug has been traditionally used to reduce pain and inflammation. Its action can be explained by reducing inflammatory chemical signals such as TNF- $\alpha$ and IL- $6 .{ }^{83}$ The beneficial effects of salsalate in metabolic disease have been observed in salsalate-treated patients. ${ }^{84-86} \mathrm{~A}$ recent study has shown that salsalate-treated mice have increased BAT activity and are resistant to diet-induced obesity. Salsalate has also resulted in a reduction in body weight in preestablished obese mice, further suggesting its therapeutic potential in obesity. Mechanistically, salsalate appears to modulate PKA activity in brown adipocytes. ${ }^{14}$

\section{B3-Adrenergic receptor agonists}

$\beta 3$-Adrenergic receptor (AR) has a critical role in BAT activation and WAT browning through PKA-mediated signaling. ${ }^{87,88}$ Cold-exposed 33 -AR knockout mice have shown reduced Ucpl expression compared to wild-type counterparts. ${ }^{89}$ Mice with triple knockout of all beta receptors $(\beta 1, \beta 2$ and $\beta 3)$ are more prone to diet-induced obesity and metabolic diseases due to defects in thermogenic activities. ${ }^{90}$ In accordance with this finding, two well-known $\beta 3$-AR agonists, isoproterenol and CL316.243, have been shown to cause marked increases in Ucp1 expression at the mRNA and protein levels in both brown and white adipocytes. ${ }^{91,92}$ Furthermore, these agonists have been shown to activate BAT and induce WAT browning in mice. ${ }^{46,93}$

\section{BAY 41-8543 (soluble guanyl cyclase)}

Cyclic GMP has also been shown to be connected to metabolic processes in BAT via its roles in regulating mitochondrial activity. ${ }^{94,95}$ Cyclic GMP-dependent pathways can be targeted as a new therapeutic approach to treat obesity and metabolic diseases. Treatment with BAY 41-8543 can sustain soluble guanylyl cyclase, reduce body fat mass and improve glucose metabolism in diet-induced obese mice. Accordingly, increased thermogenic adipocytes and higher levels of energy expenditure are observed in mice treated with BAY 41-8543. The thermogenic activity of BAY $41-8543$ is mediated by the activation of lipid uptake in BATs and increased differentiation of brown adipocytes. ${ }^{96}$ 


\section{Dinitrophenol}

Dinitrophenol (DNP) is a proton ionophore that enables protons to cross mitochondrial membranes. ${ }^{97}$ This process allows protons to leak out of the mitochondria without coupling the proton gradient to ATP synthesis. In the past, DNP was widely used as a dieting aid. However, it has been discontinued due to numerous side effects, including death in several patients. ${ }^{98}$ Acute exposure to DNP increases the metabolic rate; it also causes nausea, vomiting and headache. ${ }^{99}$ Furthermore, long-term treatment with DNP causes severe side effects, including cataracts, lesions and cardiovascular failure among others. ${ }^{98}$

\section{ENDOGENOUS THERMOGENIC SMALL MOLECULES}

\section{Serotonin}

Serotonin is a monoamine neurotransmitter. The role of serotonin and its related proteins in metabolism has also been widely investigated. ${ }^{100}$ Recent studies performed by two independent groups have reported that serotonin can negatively act on WAT browning. Whole body or adipose tissue-specific deletion of Tph1, the enzyme that produces serotonin from its precursor tryptophan has protected mice from high-fat diet-induced obesity. Such an effect is due to an increased energy expenditure. Consistently, mice injected with chemical inhibitors of Tph1 are also resistant to diet-induced obesity. ${ }^{101,102}$

\section{Lactate}

Lactate is a well-known cellular metabolite produced in muscles during anaerobic glycolysis and high-intense activity. ${ }^{103}$ Lactate has been traditionally thought as a cellular waste product. However, recent studies have revealed a new function of lactate in the browning effect. Carrière et al. presented evidence showing that cold exposure can increase circulating lactate levels and induce monocarboxylate transporter (Mct1) (lactate importer) gene expression in BAT and subcutaneous WAT. Exposure to lactate in adipocytes can stimulate mitochondrial activity, fatty acid oxidation and Ucp1 expression. These metabolic effects of lactate are negated in the presence of Mct1 inhibitors, showing that lactate transport is important in lactate-mediated WAT browning. ${ }^{104}$

\section{$\boldsymbol{\beta}$-Aminoisobutyric acid}

Exercise has been considered the best treatment for obesity and metabolic diseases. Robert et al. ${ }^{105}$ suggested that the modulation of circulating hormones and small molecules by increasing muscle activity (exercise) is closely associated with adipocytes. These authors identified $\beta$-aminoisobutyric acid (BAIBA) as a key small-molecule myokine responsible for muscle-mediated WAT browning. BAIBA treatment in human cells can increase thermogenic gene expression, lipid oxidation and oxygen consumption rates. Consistently, BAIBA treatment in mice has decreased weight gain and improved glucose tolerance through a Ppar $\alpha$-mediated mechanism. ${ }^{105}$ Thus, BAIBA can add benefit to exercise against metabolic diseases.
Nitrate

Inorganic nitrate is a cellular metabolite produced from NO oxidation. ${ }^{106}$ In the past, nitrate was considered a non-bioactive molecule; however, it has been recently reported that nitrate has anti-obesity effects via thermogenic adipocyte induction. ${ }^{107}$ Nitrate treatment can induce brown adipocyte-selective genes in primary adipocytes, and dietary nitrate supplementation can increase beige adipocyte formation in WAT depots. The effect of nitrate on WAT browning is dependent on the nitrate-nitrite-NO pathway and cyclic GMP signaling. ${ }^{107}$

\section{Adenosine}

Adenosine is an abundant ribonucleoside in the human body. This ribonucleoside plays critical roles in energy transfer and signal transduction. ${ }^{108}$ Adenosine regulates BAT lipolysis and respiration in hamster and mouse models. ${ }^{109,110}$ Adenosine treatment can activate thermogenic gene programs in both human and mouse brown adipocytes. Loss of adenosine receptor or treatment with adenosine antagonists has been shown to impair BAT-dependent thermogenesis, whereas activation of adenosine receptor prevents diet-induced obesity by inducing WAT browning and increasing energy expenditure. ${ }^{111}$

\section{UNRESOLVED ISSUES FOR THERMOGENIC SMALL MOLECULES}

Modern technologies in cell, molecular biology and genetic model systems have greatly advanced our understanding of the molecular mechanisms of cell biology, including brown adipocytes and WAT browning. In addition, recent progress in the identification of chemical regulators has further suggested that BAT should be considered promising therapeutic targets for weight management and metabolic diseases. Although recent studies have indicated that modulating energy expenditure by BAT or beige fat is highly effective in treating metabolic diseases, the significance of BAT in human physiology and unsolved issues for future therapeutic applications remain to be clarified.

\section{Therapeutic applications in humans}

Can brown fat in humans help increase energy expenditure beyond its role in maintaining body temperature? One of the main concerns is whether induction of browning in humans is a legitimate strategy against obesity and metabolic diseases. It is clear that diet-, cold- and exercise-induced WAT browning and BAT activation in mice can prevent obesity and its associated metabolic diseases. However, this strategy has not yet been deemed attractive against human metabolic diseases. Indeed, the proportion of brown fat mass in humans is nearly $1 / 10$ of that in mice. Systemic administration of catecholamines is negatively associated with human obesity; it is ineffective for human thermogenesis, with potential sympathomimetic effects. ${ }^{112}$ By contrast, $3 \mathrm{~h}$ of cold exposure in humans can increase energy expenditure by 1.8 -fold. This result is thought to be largely mediated by increased BAT activity. ${ }^{113}$ 
The amount of BAT in human is inversely correlated with BMI, suggesting that the activation of BAT can play a significant role in counteracting human metabolic diseases. ${ }^{114}$ Nevertheless, further studies are needed to determine whether WAT browning can be a valuable therapeutic strategy in humans.

\section{Potential negative outcomes by BAT stimulation}

Are there any unwanted side effects of browning (or increased BAT activity) in humans? WAT browning or increased BAT activity can protect animals from weight gain, and it can increase insulin resistance by enhancing energy expenditure and thermogenesis. As seen in DNP cases, increased uncoupling can also affect body temperature, free radical levels, injury risk and cellular metabolic rates. ${ }^{98,99}$ However, further research is needed to determine the potential harmful effects of sustained BAT activity. Alternatively, to prevent any possible negative effects, temporal control of BAT activation could be used as an essential therapeutic intervention against metabolic diseases. In addition, targeted delivery to adipocytes (discussed below) may be required to circumvent psychological and other effects on non-adipose tissues.

\section{Tissue-specific control of BAT activity}

Because currently available anti-obesity medications are often limited by their psychological or cardiovascular side effects, specific targeting of adipose tissue is needed to remove any potential side effects. Most small molecules, including berberine, butein and $\beta 3-\mathrm{AR}$ agonists, have shown effects on the neuronal system, thus suggesting that they might have unwanted actions on the cardiovascular system or neuronal tissues. By increasing the concentration of the drugs in specific tissues, but not in others, targeted drug delivery can avoid the interaction of thermogenic small molecules with healthy tissues, thereby overcoming the downfalls of conventional methods of drug delivery. Indeed, a recent discovery by the Langer group has shown that nanoparticle drug delivery methods targeting adipose tissues can be effective for obesity and insulin resistance without drug accumulation in other tissues. ${ }^{115}$ Involvement of different types of precursor cells during the induction of beige fat in subcutaneous WAT and inguinal WAT may also provide potential therapeutic approach to modulate WAT depot-specific induction of thermogenesis. ${ }^{116}$

In addition, targeting CNS or mimicking outflow of PNS to activate brown fat or WAT browning can have therapeutic potential. Autonomic hypothalamic innervation and peripheral temperature-sensitive neurons are involved in BAT activation and energy expenditure. ${ }^{177,118}$ Menthol-activated Trpm8 and capsaicin-activated Trpv1 or Trpv4 have been shown to be effective for BAT activation and weight management. ${ }^{119-121}$ The melanocortin system also plays a significant role in the sympathetic outflow, BAT activation, and energy expenditure. ${ }^{122}$ Mirabegron, a $\beta 3$-AR agonist, can activate BAT thermogenesis, induce glucose uptake, and increase energy expenditure in humans, although some concerns, such as increased heart rate and blood pressure, still exist. ${ }^{10}$ In human studies, the GLP1 analog liraglutide and dipeptidyl peptidase-4 inhibitors have been used as GLP-1 activators and have been shown to be able to activate BAT, increase WAT browning, and lower body fat. ${ }^{123,124}$ Therefore, a better understanding of neuronal control of BAT activity and selective targeting to specific neurons can also provide new optimal strategies without causing harmful effects in humans.

\section{BAT activity in other diseases}

Cancer cachexia is an atrophy of muscle and adipose tissue in cancer patients. This condition can be easily observed in cancer patients and is one of the main causes of decreased survival rates and survival periods in cancer patients. ${ }^{125}$ Cancer patients have higher energy expenditure rates, indicating that brown or beige fat might have been induced. ${ }^{126}$ Using microarray analysis in cancer clones, PTHrP has been identified as a crucial thermogenic factor secreted by cancer cells. Neutralization of PTHrP in cancer-bearing mice has abrogated the WAT browning effect by cancer. ${ }^{127}$ Another possible explanation of WAT browning by cancer cells is chronic inflammation. ${ }^{128}$ Cancer-induced chronic inflammation and IL-6 production have been reported to be responsible for WAT browning in cancer-bearing mice. Similar to PTHrP, anti-inflammatory treatments can also reduce the thermogenic activity of adipose tissues. As such, current approaches for diminishing symptoms of cancer cachexia rely on anti-inflammatory treatments. In the future, more specific targets, such as PTHrP and IL-6, should be investigated to alleviate cancer cachexia. Because numerous genetic factors and small molecules have been reported to have effects on WAT browning, approaches that reduce thermogenic adipocytes should be considered for cancer patients.

\section{MOVING FORWARD}

How can we better and effectively activate BAT? With only a handful of thermogenic small molecules being available, a few immediate strategies can be used to achieve better treatment effects. First, chemical modifications can be made to increase solubility, enhance targeted delivery, and improve controlled release. For instance, structure-activity relationship studies by chemical optimization can bring about thermogenic small molecules that are more effective against obesity and metabolic diseases. For example, optimized sirtuin inhibitors based on resveratrol have been developed, and their efficacies have been tested in diabetic animals. Modifications, such as PEGylation, encapsulation with nanoparticles, and various other approaches executed for cancer, could also be applied for diabetes treatment. Targeted delivery to regions, such as hypothalamic sites, brown adipose tissues, and white adipose tissues, can further reduce dosages and side effects in healthy tissues. This approach can also reduce the fluctuation of chemical levels in the circulation. The field of drug delivery has advanced markedly in the past few decades. Collaboration is needed to 
increase the pharmacokinetics of thermogenic small molecules in the near future.

Second, combinatorial compounds are currently being used for various diseases. Combinatory treatments with two or more drugs with different mechanisms may thus increase the beneficial metabolic effects. For example, GLP-1 agonist, liraglutide, and melanocortin receptor agonist, RM-493, have been shown to have additive metabolic benefits in diet-induced obese mice. ${ }^{129}$ Similarly, combinations of plant-derived polyphenols, such as carotenoids and isoflavones, also offer great potential to facilitate energy metabolism. Third, 'precision or individualized medicine' is emerging as a result of advancement in research technologies and clinical practice. The amounts of BAT, BMI, environments (local temperatures, exercise, and food) and genomes can vary widely among individuals. Therefore, unique approaches can be made for each patient. To achieve this, improved diagnosis of BAT activation in humans (preferably with non-invasive approaches) and identification of biomarkers would be required to dissect the differences needed for personalized medicine.

Finally, aside from focusing on the chemistry of small molecules, small molecules can also be used as tools to identify new molecular targets for therapeutic intervention and thus provide novel insights on the plasticity of adipocytes. Using the same concept, PPAR $\gamma$, MyoD and Sirtl have been identified as molecular targets of a thiazolidinedione, suberanilohydroxamic acid and resveratrol, respectively. These molecules have been highlighted as targets for the therapeutic intervention of metabolic diseases and have offered novel insights into the biology of such diseases. Likewise, the identification of Prdm4 by using butein also emphasizes the utility of small molecules in the better understanding BAT physiology. Therefore, identification of better small molecules could provide new insights into thermogenic adipocytes. These molecules can thus be used as alternative therapeutic targets to develop interventions against obesity and metabolic dysregulation. ${ }^{130}$

\section{CONCLUSION}

Recent studies of metabolism have focused on understanding the biology of BAT. This adipose tissue utilizes glucose and fatty acids as energy sources to burn calories and generate heat in response to cold exposure. ${ }^{130}$ Since the discovery of functional BAT in humans, targeting BAT is a promising therapeutic approach for treating obesity and metabolic diseases. However, further research is needed to reveal the significance of BAT (and WAT browning) in humans and its potential applications in human metabolic diseases.

\section{CONFLICT OF INTEREST}

The authors declare no conflict of interest.

\section{ACKNOWLEDGEMENTS}

This study was supported by a grant (NRF-2016M3A9B6903451 to KWP) of the Basic Science Research Program through the National Research Foundation (NRF) funded by the Ministry of Education,
Science, and Technology, Republic of Korea. This study was also supported by an NIH grant (R01DK103930 to CJV).

1 Hill JO, Peters JC. Environmental contributions to the obesity epidemic. Science 1998; 280: 1371-1374.

2 Buysschaert B, Aydin S, Morelle J, Hermans MP, Jadoul M, Demoulin N. Weight loss at a high cost: orlistat-induced late-onset severe kidney disease. Diabetes Metab 2016; 42: 62-64.

3 Filippatos TD, Derdemezis CS, Gazi IF, Nakou ES, Mikhailidis DP. Orlistat-associated adverse effects and drug interactions-a critical review. Drug Safety 2008; 31: 53-65.

4 Kose M, Emet S, Akpinar TS, Ilhan M, Gok AFK, Dadashov M et al. An unexpected result of obesity treatment: orlistat-related acute pancreatitis. Case Rep Gastroenterol 2015; 9: 152-155.

5 Douglas A, Douglas JG, Robertson CE, Munro JF. Plasma phentermine levels, weight loss and side-effects. Int J Obes 1983; 7: 591-595.

6 Rosen ED, Spiegelman BM. What we talk about when we talk about fat. Cell 2014; 156: 20-44.

7 Harms M, Seale P. Brown and beige fat: development, function and therapeutic potential. Nat Med 2013; 19: 1252-1263.

8 Cannon B, Nedergaard J. Brown adipose tissue: function and physiological significance. Physiol Rev 2004; 84: 277-359.

9 van Marken Lichtenbelt WD, Vanhommerig JW, Smulders NM, Drossaerts JM, Kemerink GJ, Bouvy ND et al. Cold-activated brown adipose tissue in healthy men. N Engl J Med 2009; 360: 1500-1508.

10 Cypess AM, Weiner LS, Roberts-Toler C, Franquet Elía E, Kessler SH, Kahn PA et al. Activation of human brown adipose tissue by a beta 3-adrenergic receptor agonist. Cell Metab 2015; 21: 33-38.

11 Symonds ME, Pope M, Budge $\mathrm{H}$. The ontogeny of brown adipose tissue. Annu Rev Nutr 2015; 35: 295-320.

12 Zhang Z, Zhang H, Li B, Meng X, Wang J, Zhang Y et al. Berberine activates thermogenesis in white and brown adipose tissue. Nat Commun 2014; 5: 5493.

13 Song NJ, Choi S, Rajbhandari P, Chang SH, Kim S, Vergnes L et al. Prdm4 induction by the small molecule butein promotes white adipose tissue browning. Nat Chem Biol 2016; 12: 479-481.

14 van Dam AD, Nahon KJ, Kooijman S, van den Berg SM, Kanhai AA, Kikuchi T et al. Salsalate activates brown adipose tissue in mice. Diabetes 2015; 64: 1544-1554.

15 Maeda H, Hosokawa M, Sashima T, Funayama K, Miyashita K. Fucoxanthin from edible seaweed, Undaria pinnatifida, shows antiobesity effect through UCP1 expression in white adipose tissues. Biochem Bioph Res Co 2005; 332: 392-397.

16 Ohno H, Shinoda K, Spiegelman BM, Kajimura S. PPAR gamma agonists induce a white-to-brown fat conversion through stabilization of PRDM16 protein. Cell Metab 2012; 15: 395-404.

17 Nicholls DG. The physiological regulation of uncoupling proteins. Biochim Biophys Acta 2006; 1757: 459-466.

18 Ricquier D. Uncoupling protein 1 of brown adipocytes, the only uncoupler: a historical perspective. Front Endocrinol 2011; 2: 85.

19 Saito M, Okamatsu-Ogura Y, Matsushita M, Watanabe K, Yoneshiro T, Nio-Kobayashi $J$ et al. High incidence of metabolically active brown adipose tissue in healthy adult humans effects of cold exposure and adiposity. Diabetes 2009; 58: 1526-1531.

20 Huang SG. Binding of fatty acids to the uncoupling protein from brown adipose tissue mitochondria. Arch Biochem Biophys 2003; 412: $142-146$.

21 Beck V, Jabůrek M, Demina T, Rupprecht A, Porter RK, Jezek P et al. Polyunsaturated fatty acids activate human uncoupling proteins 1 and 2 in planar lipid bilayers. FASEB J 2007; 21: 1137-1144.

22 Minokoshi Y, Kim YB, Peroni OD, Fryer LG, Müller C, Carling D et al. Leptin stimulates fatty-acid oxidation by activating AMP-activated protein kinase. Nature 2002; 415: 339-343.

23 Chouchani ET, Kazak L, Jedrychowski MP, Lu GZ, Erickson BK, Szpyt J et al. Mitochondrial ROS regulate thermogenic energy expenditure and sulfenylation of UCP1. Nature 2016; 532: 112-116.

24 Sears IB, MacGinnitie MA, Kovacs LG, Graves RA. Differentiationdependent expression of the brown adipocyte uncoupling protein gene: regulation by peroxisome proliferator-activated receptor gamma. Mol Cell Biol 1996; 16: 3410-3419. 
25 Seale P, Kajimura S, Yang W, Chin S, Rohas LM, Uldry M et al. Transcriptional control of brown fat determination by PRDM16. Cell Metab 2007; 6: 38-54.

26 Kajimura S, Seale P, Kubota K, Lunsford E, Frangioni JV, Gygi SP et al. Initiation of myoblast to brown fat switch by a PRDM16-C/EBP-beta transcriptional complex. Nature 2009; 460: 1154-1158.

27 Puigserver $\mathrm{P}$, Wu Z, Park CW, Graves R, Wright M, Spiegelman BM. A cold-inducible coactivator of nuclear receptors linked to adaptive thermogenesis. Cell 1998; 92: 829-839.

28 Lin J, Wu PH, Tarr PT, Lindenberg KS, St-Pierre J, Zhang CY et al. Defects in adaptive energy metabolism with CNS-linked hyperactivity in PGC-1alpha null mice. Cell 2004; 119: 121-135.

29 Uldry M, Yang W, St-Pierre J, Lin J, Seale P, Spiegelman BM. Complementary action of the PGC-1 coactivators in mitochondrial biogenesis and brown fat differentiation. Cell Metab 2006; 3: 333-341.

30 Kazak L, Chouchani ET, Jedrychowski MP, Erickson BK, Shinoda K, Cohen $\mathrm{P}$ et al. A creatine-driven substrate cycle enhances energy expenditure and thermogenesis in beige fat. Cell 2015; 163: 643-655.

31 Ukropec J, Anunciado RP, Ravussin Y, Hulver MW, Kozak LP. UCP1-independent thermogenesis in white adipose tissue of coldacclimated Ucp1 - / - mice. J Biol Chem 2006; 281: 31894-31908.

32 Long JZ, Svensson KJ, Bateman LA, Lin H, Kamenecka T, Lokurkar IA et al. The secreted enzyme PM20D1 regulates lipidated amino acid uncouplers of mitochondria. Cell 2016; 166: 424-435.

33 Kajimura S, Seale P, Tomaru T, Erdjument-Bromage H, Cooper MP, Ruas $\mathrm{JL}$ et al. Regulation of the brown and white fat gene programs through a PRDM16/CtBP transcriptional complex. Gene Dev 2008; 22 1397-1409.

34 Seale $\mathrm{P}$, Conroe HM, Estall J, Kajimura S, Frontini A, Ishibashi J et al. Prdm16 determines the thermogenic program of subcutaneous white adipose tissue in mice. J Clin Invest 2011; 121: 96-105.

35 Cohen P, Levy JD, Zhang Y, Frontini A, Kolodin DP, Svensson KJ et al. Ablation of PRDM16 and beige adipose causes metabolic dysfunction and a subcutaneous to visceral fat switch. Cell 2014; 156: 304-316.

36 Seale P, Bjork B, Yang W, Kajimura S, Chin S, Kuang S et al. PRDM16 controls a brown fat/skeletal muscle switch. Nature 2008; 454: 961-967.

37 Ohno H, Shinoda K, Ohyama K, Sharp LZ, Kajimura S. EHMT1 controls brown adipose cell fate and thermogenesis through the PRDM16 complex. Nature 2013; 504: 163-167.

38 Villanueva CJ, Vergnes L, Wang J, Drew BG, Hong C, Tu Y et al. Adipose subtype-selective recruitment of TLE3 or Prdm16 by PPAR gamma specifies lipid storage versus thermogenic gene programs. Cell Metab 2013; 17: 423-435.

39 Iida S, Chen W, Nakadai T, Ohkuma Y, Roeder RG. PRDM16 enhances nuclear receptor-dependent transcription of the brown fat- specific Ucp1 gene through interactions with mediator subunit MED1. Gene Dev 2015; 29: 308-321.

40 Harms MJ, Lim HW, Ho Y, Shapira SN, Ishibashi J. PRDM16 binds MED1 and controls chromatin architecture to determine a brown fat transcriptional program. Genes Dev 2015; 29: 298-307.

41 Kong X, Banks A, Liu T, Kazak L, Rao RR, Cohen P et al. IRF4 is a key thermogenic transcriptional partner of PGC-1 alpha. Cell 2014; 158: 69-83.

42 Davis KE, Moldes M, Farmer SR. The forkhead transcription factor FoxC2 inhibits white adipocyte differentiation. J Biol Chem 2004; 279: 42453-42461.

43 Gerin I, Bommer GT, Lidell ME, Cederberg A, Enerback S, Macdougald $\mathrm{OA}$. On the role of FOX transcription factors in adipocyte differentiation and insulin-stimulated glucose uptake. J Biol Chem 2009; 284 10755-10763.

44 You W, Fan L, Duan D, Tian L, Dang X, Wang C et al. Foxc2 over-expression in bone marrow mesenchymal stem cells stimulates osteogenic differentiation and inhibits adipogenic differentiation. Mol Cell Biochem 2014; 386: 125-134.

45 Cederberg A, Grønning LM, Ahrén B, Taskén K, Carlsson P, Enerbäck S. FOXC2 is a winged helix gene that counteracts obesity, hypertriglyceridemia, and diet-induced insulin resistance. Cell 2001; 106: 563-573.

46 Dempersmier J, Sambeat A, Gulyaeva O, Paul SM, Hudak CS, Raposo HF et al. Cold-inducible Zfp516 activates UCP1 transcription to promote browning of white fat and development of brown fat. Mol Cell 2015; 57: $235-246$.
47 Sambeat A, Gulyaeva O, Dempersmier J, Tharp KM, Stahl A, Paul SM et al. LSD1 interacts with Zfp516 to promote UCP1 transcription and brown fat program. Cell Rep 2016; 15: 2536-2549.

48 Boström P, Wu J, Jedrychowski MP, Korde A, Ye L, Lo JC et al. A PGC1-alpha-dependent myokine that drives brown-fat-like development of white fat and thermogenesis. Nature 2012; 481: 463-468.

49 Lee P, Linderman JD, Smith S, Brychta RJ, Wang J, Idelson C et al. Irisin and FGF21 are cold-induced endocrine activators of brown fat function in humans. Cell Metab 2014; 19: 302-309.

50 Jedrychowski MP, Wrann CD, Paulo JA, Gerber KK, Szpyt J, Robinson MM et al. Detection and quantitation of circulating human irisin by tandem mass spectrometry. Cell Metab 2015; 22: 734-740.

51 Fisher FM, Maratos-Flier E. Understanding the physiology of FGF21. Annu Rev Physiol 2016; 78: 223-241.

52 Fisher FM, Kleiner S, Douris N, Fox EC, Mepani RJ, Verdeguer F et al. FGF21 regulates PGC-1 alpha and browning of white adipose tissues in adaptive thermogenesis. Gene Dev 2012; 26: 271-281.

53 Nguyen KD, Qiu Y, Cui X, Goh YP, Mwangi J, David T et al. Alternatively activated macrophages produce catecholamines to sustain adaptive thermogenesis. Nature 2011; 480: 104-108.

54 Lee MW, Odegaard JI, Mukundan L, Qiu Y, Molofsky AB, Nussbaum JC et al. Activated type 2 innate lymphoid cells regulate beige fat biogenesis. Cell 2015; 160: 74-87.

55 Abd El-Wahab AE, Ghareeb DA, Sarhan EE, Abu-Serie MM, El Demellawy MA. In vitro biological assessment of Berberis vulgaris and its active constituent, berberine: antioxidants, anti-acetylcholinesterase, anti-diabetic and anticancer effects. BMC Complement Altern Med 2013; 13: 218.

56 Cernáková M, Kost'álová D, Kettmann V, Plodová M, Tóth J, Drímal J. Potential antimutagenic activity of berberine, a constituent of Mahonia aquifolium. BMC Complement Altern Med 2002; 2 : 2.

57 Brown PN, Roman MC. Determination of hydrastine and berberine in goldenseal raw materials, extracts, and dietary supplements by high-performance liquid chromatography with UV: collaborative study. J AOAC Int 2008; 91: 694-701.

58 Hashida K, Tabata M, Kuroda K, Otsuka Y, Kubo S, Makino S et al. Phenolic extractives in the trunk of Toxicodendron vernicifluum: chemical characteristics, contents and radial distribution. J Wood Sci 2014; 60: 160-168.

59 Song NJ, Yoon HJ, Kim KH, Jung SR, Jang WS, Seo CR et al. Butein is a novel anti-adipogenic compound. J Lipid Res 2013; 54: 1385-1396.

60 Sung J, Lee J. Anti-inflammatory activity of butein and luteolin through suppression of NF kappa B activation and induction of heme oxygenase-1. J Med Food 2015; 18: 557-564.

61 Zhang L, Chen W, Li X. A novel anticancer effect of butein: inhibition of invasion through the ERK $1 / 2$ and NF-kappa B signaling pathways in bladder cancer cells. FEBS Lett 2008; 582: 1821-1828.

62 Usman MG, Rafii MY, Ismail MR, Malek MA, Latif MA. Capsaicin and dihydrocapsaicin determination in chili pepper genotypes using ultra-fast liquid chromatography. Molecules 2014; 19: 6474-6488.

63 Zhang LL, Yan Liu D, Ma LQ, Luo ZD, Cao TB, Zhong J et al. Activation of transient receptor potential vanilloid type- 1 channel prevents adipogenesis and obesity. Circ Res 2007; 100: 1063-1070.

64 Luo Z, Ma L, Zhao Z, He H, Yang D, Feng X et al. TRPV1 activation improves exercise endurance and energy metabolism through PGC-1 alpha upregulation in mice. Cell Res 2012; 22: 551-564.

$65 \mathrm{~J}$ oo JI, Kim DH, Choi JW, Yun JW. Proteomic analysis for antiobesity potential of capsaicin on white adipose tissue in rats fed with a high fat diet. J Proteome Res 2010; 9: 2977-2987.

66 Ludy MJ, Moore GE, Mattes RD. The effects of capsaicin and capsiate on energy balance: critical review and meta-analyses of studies in humans. Chem Senses 2012; 37: 103-121.

67 Andero R, Ressler KJ. Fear extinction and BDNF: translating animal models of PTSD to the clinic. Genes Brain Behav 2012; 11: 503-512.

68 Liu CY, Chan CB, Ye KQ. 7,8-dihydroxyflavone, a small molecular TrkB agonist, is useful for treating various BDNF-implicated human disorders. Transl Neurodegener 2016; 5: 2.

69 Zeng Y, Wang X, Wang Q, Liu S, Hu X, McClintock SM. Small molecules activating TrkB receptor for treating a variety of CNS disorders. CNS Neurol Disord Drug Targets 2013; 12: 1066-1077.

70 Chan CB, Tse MC, Liu X, Zhang S, Schmidt R, Otten R et al. Activation of muscular TrkB by its small molecular agonist 7,8-dihydroxyflavone sex-dependently regulates energy metabolism in diet-induced obese mice. Chem Biol 2015; 22: 355-368. 
71 Peng J, Yuan JP, Wu CF, Wang JH. Fucoxanthin, a marine carotenoid present in brown seaweeds and diatoms: metabolism and bioactivities relevant to human health. Mar Drugs 2011; 9: 1806-1828.

72 Maeda H, Hosokawa M, Sashima T, Murakami-Funayama K, Miyashita K. Anti-obesity and anti-diabetic effects of fucoxanthin on diet-induced obesity conditions in a murine model. Mol Med Rep 2009; 2 : 897-902.

73 Kumar SR, Hosokawa M, Miyashita K. Fucoxanthin: a marine carotenoid exerting anti-cancer effects by affecting multiple mechanisms. Mar Drugs 2013; 11: 5130-5147.

74 Maeda H, Tsukui T, Sashima T, Hosokawa M, Miyashita K. Seaweed carotenoid, fucoxanthin, as a multi-functional nutrient. Asia Pac J Clin Nutr 2008; 17: 196-199.

75 Rosen ED, MacDougald OA. Adipocyte differentiation from the inside out. Nat Rev Mol Cell Biol 2006; 7: 885-896.

76 Fukui Y, Masui S, Osada S, Umesono K, Motojima K. A new thiazolidinedione, NC-2100, which is a weak PPAR-gamma activator, exhibits potent antidiabetic effects and induces uncoupling protein 1 in white adipose tissue of KKAy obese mice. Diabetes 2000; 49: 759-767.

77 Petrovic N, Walden TB, Shabalina IG, Timmons JA, Cannon B, Nedergaard J. Chronic peroxisome proliferator-activated receptor gamma (PPAR gamma) activation of epididymally derived white adipocyte cultures reveals a population of thermogenically competent, UCP1-containing adipocytes molecularly distinct from classic brown adipocytes. J Biol Chem 2010; 285: 7153-7164.

78 Wilson-Fritch L, Nicoloro S, Chouinard M, Lazar MA, Chui PC, Leszyk J et al. Mitochondrial remodeling in adipose tissue associated with obesity and treatment with rosiglitazone. J Clin Invest 2004; 114: 1281-1289.

79 Moisan A, Lee YK, Zhang JD, Hudak CS, Meyer CA, Prummer M et al. White-to-brown metabolic conversion of human adipocytes by JAK inhibition. Nat Cell Biol 2015; 17: 57-67.

80 Andersson ER, Lendahl U. Therapeutic modulation of Notch signallingare we there yet? Nat Rev Drug Discov 2014; 13: 359-380.

$81 \mathrm{Bi}$ PP, Kuang SH. Notch signaling as a novel regulator of metabolism. Trends Endocrin Met 2015; 26: 248-255.

82 Bi P, Shan T, Liu W, Yue F, Yang X, Liang XR et al. Inhibition of Notch signaling promotes browning of white adipose tissue and ameliorates obesity. Nat Med 2014; 20: 911-918.

83 Anderson K, Wherle L, Park M, Nelson K, Nguyen L. Salsalate, an old, inexpensive drug with potential new indications: a review of the evidence from 3 recent studies. Am Health Drug Benefits 2014; 7: 231-235.

84 Rumore MM, Kim KS. Potential role of salicylates in type 2 diabetes. Ann Pharmacother 2010; 44: 1207-1221.

85 Goldfine AB, Fonseca V, Jablonski KA, Pyle L, Staten MA, Shoelson SE. The effects of salsalate on glycemic control in patients with type 2 diabetes: a randomized trial. Ann Intern Med 2010; 152: 346-357.

86 Meex RCR, Phielix E, Moonen-Kornips E, Schrauwen P, Hesselink MKC. Stimulation of human whole-body energy expenditure by salsalate is fueled by higher lipid oxidation under fasting conditions and by higher oxidative glucose disposal under insulin-stimulated conditions. J Clin Endocr Metab 2011; 96: 1415-1423.

87 Cao W, Medvedev AV, Daniel KW, Collins S. beta-Adrenergic activation of p38 MAP kinase in adipocytes: CAMP induction of the uncoupling protein 1 (UCP1) gene requires p38 MAP kinase. J Biol Chem 2001; 276: 27077-27082.

88 Lowell BB, Spiegelman BM. Towards a molecular understanding of adaptive thermogenesis. Nature 2000; 404: 652-660.

89 Jimenez M, Barbatelli G, Allevi R, Cinti S, Seydoux J, Giacobino JP et al. beta(3)-Adrenoceptor knockout in C57BL/6J mice depresses the occurrence of brown adipocytes in white fat. Eur J Biochem 2003; 270: 699-705.

90 Bachman ES, Dhillon H, Zhang CY, Cinti S, Bianco AC, Kobika BK et al. betaAR signaling required for diet-induced thermogenesis and obesity resistance. Science 2002; 297: 843-845.

91 Wu J, Boström P, Sparks LM, Ye L, Choi JH, Giang AH et al. Beige adipocytes are a distinct type of thermogenic fat cell in mouse and human. Cell 2012; 150: 366-376.

92 Cinti S, Cancello R, Zingaretti MC, Ceresi E, De Matteis R, Giordano A et al. CL316,243 and cold stress induce heterogeneous expression of UCP1 mRNA and protein in rodent brown adipocytes. J Histochem Cytochem 2002; 50: 21-31.

93 Wang J, Liu R, Wang F, Hong J, Li X, Chen M et al. Ablation of LGR4 promotes energy expenditure by driving white-to-brown fat switch. Nat Cell Biol 2013; 15: 1455-1463.
94 Haas B, Mayer P, Jennissen K, Scholz D, Berriel Diaz M, Bloch W et al. Protein kinase $\mathrm{G}$ controls brown fat cell differentiation and mitochondrial biogenesis. Sci Signal 2009; 2: ra78.

95 Mitschke MM, Hoffmann LS, Gnad T, Scholz D, Kruithoff K, Mayer P et al. Increased CGMP promotes healthy expansion and browning of white adipose tissue. FASEB J 2013; 27: 1621-1630.

96 Hoffmann LS, Etzrodt J, Willkomm L, Sanyal A, Scheja L, Fisher AW et al. Stimulation of soluble guanylyl cyclase protects against obesity by recruiting brown adipose tissue. Nat Commun 2015; 6: 7235.

97 Kessler RJ, Tyson CA, Green DE. Mechanism of uncoupling in mitochondria: uncouplers as ionophores for cycling cations and protons. Proc Natl Acad Sci USA 1976; 73: 3141-3145.

98 Grundlingh J, Dargan PI, El-Zanfaly M, Wood DM. 2,4-dinitrophenol (DNP): a weight loss agent with significant acute toxicity and risk of death. J Med Toxicol 2011; 7: 205-212.

99 Petróczi A, Ocampo JA, Shah I, Jenkinson C, New R, James RA et al. Russian roulette with unlicensed fat-burner drug 2,4-dinitrophenol (DNP): evidence from a multidisciplinary study of the internet, bodybuilding supplements and DNP users. Subst Abuse Treat Prev Policy 2015; 10: 39.

100 Tecott LH. Serotonin and the orchestration of energy balance. Cell Metab 2007; 6: 352-361.

101 Crane JD, Palanivel R, Mottillo EP, Bujak AL, Wang H, Ford RJ et al. Inhibiting peripheral serotonin synthesis reduces obesity and metabolic dysfunction by promoting brown adipose tissue thermogenesis. Nat Med 2015; 21: 166-172.

102 Oh CM, Namkung J, Go Y, Shong KE, Kim K, Kim H et al. Regulation of systemic energy homeostasis by serotonin in adipose tissues. Nat Commun 2015; 6: 6794.

103 Rogatzki MJ, Ferguson BS, Goodwin ML, Gladden LB. Lactate is always the end product of glycolysis. Front Neurosci 2015; 9: 22.

104 Carrière A, Jeanson Y, Berger-Müller S, André M, Chenouard V, Arnaud E et al. Browning of white adipose cells by intermediate metabolites: an adaptive mechanism to alleviate redox pressure. Diabetes 2014; 63: 3253-3265.

105 Roberts LD, Boström P, O'Sullivan JF, Schinzel RT, Lewis GD, Dejam A et al. Beta-aminoisobutyric acid induces browning of white fat and hepatic beta-oxidation and is inversely correlated with cardiometabolic risk factors. Cell Metab 2014; 19: 96-108.

106 Lundberg JO, Weitzberg E, Gladwin MT. The nitrate-nitrite-nitric oxide pathway in physiology and therapeutics. Nat Rev Drug Discov 2008; 7: 156-167.

107 Roberts LD, Ashmore T, Kotwica AO, Murfitt SA, Fernandez BO, Fellisch $\mathrm{M}$ et al. Inorganic nitrate promotes the browning of white adipose tissue through the nitrate-nitrite-nitric oxide pathway. Diabetes 2015; 64: 471-484.

108 Burnstock G. Physiology and pathophysiology of purinergic neurotransmission. Physiol Rev 2007; 87: 659-797.

109 Schimmel RJ, McCarthy L. Role of adenosine as an endogenous regulator of respiration in hamster brown adipocytes. Am J Physiol 1984; 246: C301-C307.

110 Szillat D, Bukowiecki LJ. Control of brown adipose tissue lipolysis and respiration by adenosine. Am J Physiol 1983; 245: E555-E559.

111 Gnad T, Scheibler S, von Kügelgen I, Scheele C, Kilić A, Glöde A et al. Adenosine activates brown adipose tissue and recruits beige adipocytes via A2A receptors. Nature 2014; 516: 395-399.

112 Guo T, Marmol P, Moliner A, Björnholm M, Zhang C, Shokat KM et al. Adipocyte ALK7 links nutrient overload to catecholamine resistance in obesity. Elife 2014; 3: e03245.

113 Ouellet V, Labbé SM, Blondin DP, Phoenix S, Guérin B, Haman F et al. Brown adipose tissue oxidative metabolism contributes to energy expenditure during acute cold exposure in humans. J Clin Invest 2012; 122: $545-552$.

114 Zingaretti MC, Crosta F, Vitali A, Guerrieri M, Frontini A, Cannon B et al. The presence of UCP1 demonstrates that metabolically active adipose tissue in the neck of adult humans truly represents brown adipose tissue. FASEB J 2009; 23: 3113-3120.

115 Xue Y, Xu X, Zhang XQ, Farokhzad OC, Langer R. Preventing diet-induced obesity in mice by adipose tissue transformation and angiogenesis using targeted nanoparticles. Proc Natl Acad Sci USA 2016; 113: 5552-5557.

116 Chau YY, Hastie N. Wt1, the mesothelium and the origins and heterogeneity of visceral fat progenitors. Adipocyte 2015; 4: 217-221.

117 Bartness TJ, Vaughan $\mathrm{CH}$, Song CK. Sympathetic and sensory innervation of brown adipose tissue. Int J Obesity 2010; 34: S36-S42. 
118 Zhang W, Bi S. Hypothalamic regulation of brown adipose tissue thermogenesis and energy homeostasis. Front Endocrinol 2015; 6: 136.

$119 \mathrm{Ma} \mathrm{S}, \mathrm{Yu} \mathrm{H}$, Zhao Z, Luo Z, Chen J, Ni Y et al. Activation of the cold-sensing TRPM8 channel triggers UCP1-dependent thermogenesis and prevents obesity. J Mol Cell Biol 2012; 4: 88-96.

120 Baboota RK, Singh DP, Sarma SM, Kaur J, Sandhir R, Boparai RK et al. Capsaicin induces 'Brite' phenotype in differentiating 3T3-L1 preadipocytes. PLOS ONE 2014; 9: e103093.

121 Ye L, Kleiner S, Wu J, Sah R, Gupta RK, Banks AS et al. TRPV4 is a regulator of adipose oxidative metabolism, inflammation, and energy homeostasis. Cell 2012; 151: 96-110.

122 Richard D, Carpentier AC, Dore G, Ouellet V, Picard F. Determinants of brown adipocyte development and thermogenesis. Int J Obes 2010; 34 (Suppl 2): S59-S66.

123 Beiroa D, Imbernon M, Gallego R, Senra A, Herranz D, Villarroya F et al. GLP-1 agonism stimulates brown adipose tissue thermogenesis and browning through hypothalamic AMPK. Diabetes 2014; 63 : 3346-3358.

124 Shimasaki T, Masaki T, Mitsutomi K, Ueno D, Gotoh K, Chiba S et al. The dipeptidyl peptidase-4 inhibitor des-fluoro-sitagliptin regulates brown adipose tissue uncoupling protein levels in mice with diet-induced obesity. PLOS ONE 2013; 8: e63626.

125 Tisdale MJ. Cachexia in cancer patients. Nat Rev Cancer 2002; 2 862-871.

126 Hyltander A, Drott C, Korner U, Sandstrom R, Lundholm K. Elevated energy expenditure in cancer patients with solid tumours. Eur J Cancer 1991; 27: 9-15.
127 Kir S, White JP, Kleiner S, Kazak L, Cohen P, Baracos VE et al. Tumour-derived PTH-related protein triggers adipose tissue browning and cancer cachexia. Nature 2014; 513: 100-104.

128 Petruzzelli M, Schweiger M, Schreiber R, Campos-Olivas R, Tsoli M, Allen J et al. A switch from white to brown fat increases energy expenditure in cancer-associated cachexia. Cell Metab 2014; 20: 433-447.

129 Clemmensen C, Finan B, Fischer K, Tom RZ, Legutko B, Sehrer L et al. Dual melanocortin-4 receptor and GLP-1 receptor agonism amplifies metabolic benefits in diet-induced obese mice. EMBO Mol Med 2015; 7: 288-298.

130 Lee YH, Jung YS, Choi D. Recent advance in brown adipose physiology and its therapeutic potential. Exp Mol Med 2014; 46: e78.

131 Mao T, Yan Q, Zhou F, Shen Y. Isolation and identification of berberine from cell cultures of Coptis chinensis. Chin J Biotechnol 1997; 13: 193-199.

(c) (1) (2) (2) This work is licensed under a Creative Commons Attribution-NonCommercial-ShareAlike 4.0 International License. The images or other third party material in this article are included in the article's Creative Commons license, unless indicated otherwise in the credit line; if the material is not included under the Creative Commons license, users will need to obtain permission from the license holder to reproduce the material. To view a copy of this license, visit http:// creativecommons.org/licenses/by-nc-sa/4.0/ 